\title{
Development of Spray-Dried Sildenafil Citrate - $a$-cyclodextrin Complexes for Use in Dry Powder Inhalers
}

\author{
Apichart Atipairin ${ }^{1,2}$, Somchai Sawatdee ${ }^{1,2, *}$ \\ 'Drug and Cosmetics Excellence Center, Walailak University, Thasala, Nakhon Si Thammarat, THAILAND. \\ ${ }^{2}$ School of Pharmacy, Walailak University, Thasala, Nakhon Si Thammarat, THAILAND.
}

\begin{abstract}
Background: Sildenafil citrate is a drug used in the treatment of pulmonary hypertension. The development of sildenafil citrate complexed with $\alpha$-cyclodextrin as dry powder inhaler (DPI) should enhance its solubility in the lung. Methods: Sildenafil citrate was dissolved with $\alpha$-cyclodextrin solution at $\mathrm{pH} 4.5$ to obtain inclusion complexes. The complex solution was spray-dried to make spheroidal powder. The sildenafil DPI formulations were mixed with coarse lactose and fine lactose as carriers and then filled in capsule no. 2. Three different ratios of course to fine lactose were used (1:1 (\#1), 2:1 (\#2) and 3:1 (\#3)) to optimize the performance and aerosol properties. The fine particle fraction (FPF), mass median aerodynamic diameter (MMAD) and geometric standard deviation (GSD) were used to evaluate the in vitro drug delivery performance in the lung by in vitro. Results: The proportion of sildenafil in formulations \#1, \#2, \#3 was $100.2 \%$ $\pm 0.1 \%, 100.1 \% \pm 0.2 \%$ and $98.9 \% \pm 0.1 \%$, respectively. The aerosol properties of the best formulation (\#2) were as follows: an ED of $85.5 \pm$
\end{abstract}

$0.5 \%$, an FPF of $56.6 \pm 2.3 \%$, an MMAD of $3.2 \pm 0.6 \mu \mathrm{m}$ and a GSD of $1.02 \pm 0.01$. Conclusion: Sildenafil citrate complexed with $\alpha$-cyclodextrin was successfully developed for a DPI by using coarse and fine lactose monohydrate in a 2:1 ratio.

Key words: Sildenafil citrate, Dry powder inhaler, Alpha-cyclodextrin, Complexed, Fine particle fraction, MMAD.

\section{Correspondence}

Dr. Somchai Sawatdee

Head of Drug and Cosmetics Excellence Center and Associate Professor at School of Pharmacy, Walailak University, Thasala, Nakhon Si Thammarat-80161, THAILAND

Phone no: +66-891986056

Email: somchai086@hotmail.com

DOI: 10.5530/ijpi.2020.1.17

\section{INTRODUCTION}

Sildenafil or sildenafil citrate is a drug used in the treatment of erectile dysfunction and pulmonary hypertension. ${ }^{1,2}$ The typical dosage forms of sildenafil are oral tablets or intravenous administration. ${ }^{3-5}$ Currently, sildenafil has been developed as an inhaler to treat pulmonary hypertension for delivered to the lung included of dry powder inhaler (DPI), metered-dose inhaler and nebulizer for avoiding unwanted systemic side-effects and rapid drug action. ${ }^{6-11}$ There are previously report sildenafil citrate complexed with $\alpha$-cyclodextrin to enhance the solubility of sildenafil as a linear function of cyclodextrin concentration. ${ }^{12}$ The complex of sildenafil citrate and $\alpha$-cyclodextrin is one-to-one complex formation. ${ }^{7,12}$ Currently, there are no reports regarding the formulation of sildenafil complexed with $\alpha$-cyclodextrin for use in a DPI. Development of sildenafil citrate complexed with $\alpha$-cyclodextrin is beneficial due to its enhanced solubility in the lung. The objective of this study is to investigate the aerosolized properties of spray-dried sildenafil citrate complexed with $\alpha$-cyclodextrin and determine the feasibility of developing and optimizing this formulation in the future studies.

\section{MATERIALS AND METHODS}

\section{Materials}

Sildenafil citrate and a reference standard (potency $=99.4 \%$ ) were obtained from Smilax Laboratories Limited (Hyderabad, India). The $\alpha$-cyclodextrin (CAVAMAX ${ }^{\circledR}$ W6 Pharma) was purchased from ISP Pharmaceuticals (Wayne, NJ, USA). Lactose monohydrate was obtained from Ajax Finechem Pty Ltd. (Australia).

\section{Preparation of spray-dried sildenafil citrate complexed with a-cyclodextrin}

Sildenafil citrate $(20 \mathrm{~g})$ was dissolved in $1000 \mathrm{~mL}$ of $\alpha$-cyclodextrin solution at $\mathrm{pH} 4.5$ until a clear solution was obtained. This solution was immediately sprayed at a flow rate of $10 \mathrm{~mL} / \mathrm{min}$ utilizing a spray dryer system (Anhydro, Copenhagen, Denmark) equipped with a nozzle ( 0.2 $\mathrm{mm}$ diameter) for atomization. Spray-dried powder formulations were collected via cyclone. The spray conditions were optimized beforehand to obtain a particle size $<5 \mu \mathrm{m}$. The spray-dried formulation of sildenafil citrate with $\alpha$-cyclodextrin complexed powder was stored over silica gel in a desiccator at $25^{\circ} \mathrm{C} \pm 2^{\circ} \mathrm{C}$.

\section{Preparation of sildenafil citrate dry powder inhaler}

Dosing of sildenafil for pulmonary administration was performed according to Sawatdee and co-authors with $20 \mu \mathrm{g}$ sildenafil per puff. ${ }^{6,7}$ Lactose monohydrate, which was used as a carrier, was reduced by a grinding mill (Fritsch, Germany) for $3 \mathrm{~h}$ to obtain micronized particles (particle size ranged from $1-5 \mu \mathrm{m}$ for use as a fine carrier). The coarse lactose monohydrate particles $(50-100 \mu \mathrm{m})$ were used from the original material. Sildenafil citrate and $\alpha$-cyclodextrin complexed with lactose monohydrate (fine and coarse particles) were dried at $37^{\circ} \mathrm{C}$ for $12 \mathrm{~h}$ in a vacuum oven (Precision Scientific, Inc., Chicago, USA). Three different DPI formulations varied based on the ratio of fine to coarse carrier particles $(1: 1,2: 1$ and $3: 1$ by weight $)$ to optimize the suitable aerosol properties (Table 1). A thousand doses (20 mg total weight per dose) of each formulation were weighed, transferred to a glass bottle, sealed with 
cellophane tape and mixed for $20 \mathrm{~min}$. Each dose (total weight: $20 \mathrm{mg}$ ) was weighed and used to fill gelatin capsule \#2 for future studies.

\section{Analysis of sildenafil citrate by high-performance liquid chromatography}

Sildenafil citrate was analyzed by high-performance liquid chromatography (HPLC) according to the method described by previous reports. ${ }^{6,7,13}$ The HPLC system (Waters, Milford MA, USA) consisted of a solvent delivery pump equipped with an in-line degasser (Waters 1525 binary HPLC pump), a sample loop with an injection volume of $20 \mu \mathrm{L}$ and a Waters 2707 auto sampler. Data was recorded using Empower 2 software. Separations were performed on a reversed-phase stainless steel column (ACE 5 C18-AR; Advanced Chromatography Technologies, Aberdeen, Scotland) $(250 \mathrm{~mm}$ long $\times 4.6 \mathrm{~mm}$ internal diameter $)$ filled with $5 \mu \mathrm{m}$ octadecylsilane and maintained at $25^{\circ} \mathrm{C}$. The mobile phase consisted of a degassed mixture of $0.2 \mathrm{M}$ ammonium acetate buffer and acetonitrile in a ratio of 40:60 by volume at ambient temperature; the $\mathrm{pH}$ was adjusted to 7.0 with $0.1 \mathrm{~N} \mathrm{NaOH}$ prior to use. The flow rate was maintained at $1.0 \mathrm{~mL} / \mathrm{min}$ and the separation was monitored by UV detection (Waters 2998 photodiode array detector) at a wavelength of $240 \mathrm{~nm}$.

\section{Content of sildenafil}

Sildenafil citrate DPIs were analyzed by HPLC as described in the previous section. Ten randomly selected capsules of each formulation (\#1, \#2, \#3) were analyzed to measure the content of sildenafil. The formulations were removed from the capsule shell, dissolved with the mobile phase and analyzed with HPLC.

\section{Aerosol property evaluation}

All three formulations were analyzed to determine aerosol properties by using an Andersen Cascade Impactor (Copley Scientific, Nottingham, United Kingdom). Each formulation was kept in capsule \#1 and then loaded into the Rotahaler ${ }^{\circledR}$ (GlaxoSmithKline, Germany) for evaluation. The Rotahaler ${ }^{\circledR}$ mouthpiece was connected and attached with the mouthpiece adaptor to produce an airtight seal between the inhaler mouthpiece and the induction port. A vacuum pump was used to draw air through the cascade impactor and to calibrate the airflow rate $(28.5 \mathrm{~L} / \mathrm{min}) .{ }^{14}$ The valve was kept depressed for a sufficient duration to ensure that the dose was completely discharged. This step was repeated until five doses had been discharged. After the last dose was discharged, the inhaler was removed from the mouthpiece adaptor. The mouthpiece adaptor and the induction port were rinsed with the mobile phase and diluted to $10 \mathrm{~mL}$ in a volumetric flask. The cascade impact or was dissembled and the drug from each stage and its collection plate or filter were rinsed in a separate volumetric flask. Each fraction was adjusted to a specified volume and the amount of drug deposited on each plate was determined by HPLC. The emitted dose (ED) is the dose emission from the device was evaluated. The fine particle fraction (FPF), mass median aerodynamic diameter (MMAD) and geometric standard deviation (GSD) values were calculated.

\section{RESULTS}

This preliminary experiment was performed to evaluate a complex of sildenafil citrate with $\alpha$-cyclodextrin delivered as DPI. The assay content of sildenafil in each formulation is shown in Table 2 . These in vitro studies also evaluated the aerosol performance of DPI formulation based on the ED, FPF, MMAD and GSD (Table 2).
Table 1: Composition of sildenafil dry powder formulations.

\begin{tabular}{ccccc|}
\hline Formulation & \multicolumn{4}{c}{ Composition (mg) } \\
\cline { 2 - 5 } & $\begin{array}{c}\text { Sildenafil } \\
\text { complexed with } \\
\text { a-cyclodextrin* }\end{array}$ & $\begin{array}{c}\text { Coarse } \\
\text { lactose }\end{array}$ & Fine lactose & $\begin{array}{c}\text { Total dose } \\
(\mathrm{mg})\end{array}$ \\
\hline$\# 1$ & 0.069 & 10.0 & 10.0 & 20 \\
$\# 2$ & 0.069 & 13.3 & 6.7 & 20 \\
$\# 3$ & 0.069 & 15.0 & 5.0 & 20 \\
\hline
\end{tabular}

*Sildenafil citrate complexed with a-cyclodextrin equivalent to $20 \mu \mathrm{g}$ sildenafil

Table 2: The assay content and aerosol properties of sildenafil citrate $\alpha$-cyclodextrin complexes formulations.

\begin{tabular}{cccc}
\hline Test $(\boldsymbol{n}=10)$ & \multicolumn{3}{c}{ Formulation no. } \\
& $\# 1$ & $\# 2$ & $\# 3$ \\
\hline Content of sildenafil (\% LA) & $100.2 \pm 0.1$ & $100.1 \pm 0.2$ & $98.9 \pm 0.1$ \\
Emitted dose (ED, \%) & $64.7 \pm 2.1$ & $85.5 \pm 0.5$ & $55.6 \pm 1.1$ \\
Fine particle fraction (FPF, \%) & $33.7 \pm 1.2$ & $56.6 \pm 2.3$ & $29.5 \pm 1.5$ \\
MMAD ( $\mu$ m) & $3.0 \pm 0.7$ & $3.2 \pm 0.6$ & $4.2 \pm 2.1$ \\
GSD & $1.25 \pm 0.5$ & $1.02 \pm 0.01$ & $1.55 \pm 0.24$ \\
\hline
\end{tabular}

\section{DISCUSSION}

As reported in previous studies, sildenafil citrate can form inclusion complexes with $\alpha$-cyclodextrin via a $1: 1$ stoichiometric ratio. ${ }^{6,12,15,16}$ The solubility of sildenafil increased by raising the concentration of $\alpha$-cyclodextrin. To obtain $20 \mu \mathrm{g}$ of sildenafil per inhalation dose, we used $28 \mu \mathrm{g}$ of a sildenafil citrate salt. To promote the 1:1 complex formation of sildenafil and $\alpha$-cyclodextrin, we used $41 \mu \mathrm{g}$ of $\alpha$-cyclodextrin $\mathrm{w}$ to complete the inclusion complex with $28 \mu$ with sildenafil citrate ${ }^{6,12,15,16}$ The spray-dried complex of sildenafil citrate with $\alpha$-cyclodextrin was free-flowing and had a spheroidal shape (observed by light microscope) that was suitable for use in DPIs. ${ }^{17}$ We chose the Rotahaler ${ }^{\circledR}$ in this experiment to deliver the dry powder due to its ease of use and high-performance delivery of drugs to the lung. ${ }^{18}$ The EDs of spray-dried sildenafil citrate with $\alpha$-cyclodextrin complexes ranged from 55.6 to $85.5 \%$ and the FPFs were in the range of $29.5 \%-56.6 \%$. The formulations used coarse and fine lactose carrier in a ratio of 2:1 resulting in highest value of ED and FPF. Fine carrier particles are used to improve DPI performance. ${ }^{19}$ Although the mechanism through which fine carrier particles improve drug delivery is unclear, the literature suggests that fine carriers with similar geometric sizes to the drug should be used. ${ }^{19-21}$ The $2: 1$ ratio of fine to coarse lactose monohydrate carrier particles may be suitable for weak interactions and may decrease the aggregation of sildenafil citrate with $\alpha$-cyclodextrin complexed particles and lactose monohydrate to better deliver the drug deep into the lung. All three formulations show MMAD values between 3-4 $\mu \mathrm{m}$, which are suitable for drug deposition in the lung. These results showed that spray-dried sildenafil citrate complexed with $\alpha$-cyclodextrin has strong potential for future drug development. For the next steps, novel techniques will be applied to the optimization of this drug formulation. Studies regarding sildenafil complexed with carriers, the solubility of the drug in each formulation and the efficiency/toxicity of DPI need to be determined in future reports. 


\section{CONCLUSION}

Sildenafil citrate complexed with $\alpha$-cyclodextrin and formulated for a DPI using coarse and fine lactose monohydrate particles (2:1) as carriers is suitable for in vitro delivery to the lung.

\section{ACKNOWLEDGEMENT}

This research was partially supported by the new strategic research $(\mathrm{P} 2 \mathrm{P})$ project, Walailak University, Thailand. The authors would like to thank the Drug and Cosmetics Excellence Center of Walailak University for their Support and provision of required materials.

\section{CONFLICT OF INTEREST}

The authors declare that there are no conflicts of interest.

\section{ABBREVIATIONS}

DPI: Dry powder inhaler; FPF: Fine particle fraction; MMAD: Mass median aerodynamic diameter; GSD: Geometric standard deviation; ED: Emitted dose; HPLC: High-performance liquid chromatography; UV: Ultraviolet.

\section{REFERENCES}

1. Ghofrani HA, Osterloh IH, Grimminger F. Sildenafil: From angina to erectile dysfunction to pulmonary hypertension and beyond. Nat Rev Drug Discov. 2006;5(8):689-702.

2. Chocalingam A, Gnanavelu G, Venkatesan S, Elangovan S, Jagannathan V, Subramaniam $T$, et al. Efficacy and optimal dose of sildenafil in primary pulmonary hypertension. Int J Cardiol. 2005;99(1):91-5.

3. Fink HA, McDonald R, Rutks IR, Nelson DB, Wilt TJ. Sildenafil for male erectile dysfunction: A systemic review and meta-analysis. Arch Intern Med. 2002;162(12):1349-60.

4. Stultz J, Puthoff T, JrBackes C, Nahata MC. Intermittent intravenous sildenafil for pulmonary hypertension management in neonates and infants. Am J Health-Syst Pharm. 2013;70(5):407-13.

5. Rashid J, Patel B, Nozik-Grayck E, McMurtry IF, Stenmark KR, Ahsan F. Inhaled sildenafil as an alternative to oral sildenafil in the treatment of pulmonary arterial hypertension (PAH). J Control Release. 2017;250:96-106.

6. Sawatdee S, Phetmung H, Srichana T. Sildenafil citrate monohydrate-cyclodextrin nanosuspension complexes for use in metered-dose inhalers. Int J Pharm.
2013;455(1-2):248-58.

7. Sawatdee S, Hiranphan P, Laphanayos K Srichana T. Evaluation of sildenafil pressurized metered dose inhalers as a vasodilator in umbilical blood vessels of chicken egg embryos. Eur J Pharm Biopharm. 2014;86(1):90-7.

8. Valle MJD, González PG, Ribeiro MP, Araujo ARTS, Navarro AS. Sildenafil citrate liposomes for pulmonary delivery by ultrasonic nebulization. Appl Sci. 2018;8(8):1291.

9. Nguyen TT, Yi, E, Hwang K, Cho C, Park C, Kim J, et al. Formulation and evaluation of carrier-free dry powder inhaler containing sildenafil. Drug Deliv Trans Res. 2019;9(1):319-33.

10. Chunhachaichana C, Sritharadol R, Sawatdee S, Heng PWS, Srichana T. Development of nanodispersion-based sildenafil metered-dose inhalers stabilized by poloxamer 188: A potential candidate for the treatment of pulmonary arterial hypertension. Pharm Dev Technol. 2019;24(10):1218-28.

11. Ghanbarzadeh S, Saeeneya Y, Valizadeh H, Nokhodchi A, Hamishehkar H. Carrier free dry powder formulation of sildenafil for potential application in pulmonary arterial hypertension. Pharmazie. 2016;71(4):181-4.

12. Atipairin A, Sawatdee S. Inclusion complexes between sildenafil citrate and cyclodextrin enhance drug solubility. Asian J Pharm Sci. 2016;11:104-5.

13. Sawatdee S, Atipairin A, Sae YA, Srichana T, Changsan N. Enhanced dissolution of sildenafil citrate as dry foam tablets. Pharm Dev Technol. 2019;24(1):1-11.

14. British Pharmacopoeia Commission. British Pharmacopoeia 2011. London:TSO. 2011.

15. Al Omari MM, Zughul MB, Badwan AA Sildenafil/cyclodextrin complexation: stability constants, thermodynamics and guest-host interactions probed by $1 \mathrm{H}$ NMR and molecular modeling studies. J Pharm Biomed Anal. 2006;41(3):85765.

16. Swart H, Knoetze S. Inclusion complexes of alpha-cyclodextrin and sildenafil salt, Patent No. WO2010/070617Al. 2010.

17. Crowder TM, Rosati JA, Schroeter JD, Hickey AJ, Martonen TB. Fundamental effects of particle morphology on lung delivery: predictions of Stokes' law and the particular relevance to dry powder inhaler formulation and development. Pharm Res. 2002;19(3):239-45.

18. Adams WP, Lee SL, Plourde R, Lionberger RA, Bertha CM, Doub WH, et al. Effect of device and formulation on in vitro performance of dry powder inhalers. AAPS J. 2012;14(3):400-9.

19. Peng $T$, Lin $S$, Niu $B$, Wang $X$, Huang $Y$, Zhang $X$, et al. Influence of physical properties of carrier on the performance of dry powder inhalers. Acta Pharm Sin. 2016;6(4):308-18.

20. Beilmann B, Kubiak R, Grab P, Häusler H, Langguth P. Effect of interactive ternary mixtures on dispersion characteristics of ipratropium bromide in dry powder inhaler formulations. AAPS Pharm Sci Tech. 2007;8(2):E32-9.

21. Kinnunen $H$, Hebbink $G$, Peters $H$, Shur J, Price R. An investigation into effect of fine lactose particles on the fluidization behavior and aerosolization perfor mance of carrier-based dry powder inhaler formulations. AAPS Pharm SciTech. 2014;15(4):898-909. 